\title{
O Conselho Gestor do Parque Estadual Marinho de Areia Vermelha (Cabedelo, Paraíba) como espaço público de diálogo ambiental
}

\author{
Karina Massei ${ }^{1}$, Rogério dos Santos Ferreira ${ }^{2}$ \\ 1Programa de Pós-Graduação em Desenvolvimento e Meio Ambiente. Centro de \\ Ciências Exatas e da Natureza. Universidade Federal da Paraíba. Campus I. João \\ Pessoa-PB (CEP 58050-900). \\ 2Programa de Pós-Graduação em Geografia. Centro de Ciências Exatas e da Natureza. \\ Universidade Federal da Paraíba. Campus I. João Pessoa-PB (CEP 58050-900). \\ E-mail: rogeriosertaomar@gmail.com.
}

Resumo. Este artigo versa sobre a necessidade de constituição e pratica do Conselho Gestor de Unidades de Conservação enquanto a organização de espaços públicos ambientais de debate e aprendizado sobre a participação publica nas decisões de governo. Tendo como realidade estudada o Conselho Gestor do Parque Estadual Marinho de Areia Vermelha (Município de Cabedelo, Estado da Paraíba) e seu histórico de atuação. Foi utilizada a metodologia da pesquisa participante, leitura bibliográfica e práticas de visitação no campo. Sendo discutida a gestão ambiental em Unidades de Conservação, Participação popular na coisa publica e seus modelos de atuação, bem como, resultados de intervenção e histórico de entendimento e pratica desta modalidade de governança instituída por Lei. Sendo posto como resultado final a necessidade de maior reconhecimento e formação social para esta demanda.

Palavras-chave: Unidade de Conservação; Sistema Nacional de Unidades de Conservação; Política Nacional do Meio Ambiente; Conselho gestor; Participação social.

Abstract. The Management Council of the Areia Vermelha State Marine Park (Cabedelo, Paraíba) as a public space for environmental dialogue. This article discusses the need for constitution and practice of the Conservation Unit Management Council while organizing environmental public spaces for debate and learning about public participation in government decisions. Having as reality studied the Management Council of the Parque Estadual Marinho de Areia Vermelha (Municipality of Cabedelo, State of Paraíba) and its history of performance. The methodology of the participant research, bibliographic reading and visitation practices in the field was used. Environmental management is discussed in Conservation Units, popular participation in the public thing and its models of action, as well as, intervention results and history of understanding and practice of this modality of governance instituted by Law. The final result is the need for greater Recognition and social formation for this demand.

Keywords: Conservation Unit; National System of Conservation Units; National Environment Policy; Board of Directors; Social participation.

Recebido:

24/10/2016

Aceito:

03/12/2016

Publicado:

31/12/2016

Acesso Aberto Artigo completo

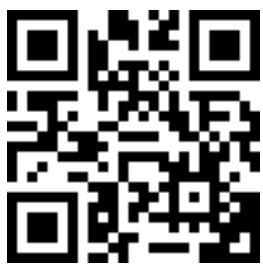

\section{ORCID}

(1) 0000-0003-4152-1147 Karina Massei

(1) 0000-0002-7099-8035 Rogério dos Santos Ferreira 


\section{Introdução}

Historicamente, desde a fase dos primeiros colonizadores portugueses, a natureza é objeto de exploração para fins econômicos, a exemplo do comércio internacional do pau-brasil, usado como madeira ou para a extração de seus pigmentos como corante.

Desde outrora aos dias atuais, vem ocorrendo mesmo que de formas distintas, fases de exploração dos recursos naturais que propiciam as bases para a legislação ambiental brasileira e sua aplicação na gestão ambiental (Câmara, 2013).

Em termos históricos, a democracia brasileira pode ser considerada um processo recente, sendo interrompida por períodos de governo autoritário, e consequentemente afetada profundamente pela impossibilidade do exercício de cidadania e de o País se constituir, de fato, num Estado democrático com canais institucionais, mais diretos de participação e decisão (Gohn, 2004; Baquero, 2012).

Na década de 1980, diante da ação dos denominados movimentos sociais urbanos e da atuação política organizada de certos setores profissionais corporativos, principalmente na Saúde, na Educação e na Assistência Social, foram obtidos avanços no sentido da formação de espaços públicos formais ou não formais. O resultado dessa movimentação política se deu com a promulgação da Constituição de 1988, que, em seu artigo 10, prevê que "Todo poder emana do povo, que o exerce indiretamente, através de seus representantes eleitos, ou diretamente, nos termos desta Constituição" (IBASE, 2006).

Assim, institui-se a possibilidade de criação de meios de participação da sociedade, sendo exemplos como: plebiscito, referendo, iniciativa popular de lei, audiências públicas, conselhos, comitês, fóruns, orçamento participativo, ouvidorias, etc. Nesse sentido, a participação da sociedade civil em processos de decisão política e a formação de espaços públicos nos quais os cidadãos e cidadãs possam debater e deliberar sobre temas de interesse público assumem papel central (Santos et al., 2005). O artigo 225, da Constituição Federal (Brasil, 1988), representou o marco de uma nova mentalidade, ao atribuir ao poder público e à coletividade o dever compartilhado de preservar o meio ambiente para as presentes e futuras gerações.

O estabelecimento da Política Nacional do Meio Ambiente, instituída pela Lei no 6.938/1981 (Brasil, 1981), incorpora princípios da democratização das políticas públicas e da participação social no processo de tomada de decisão e na ação descentralizada do Estado.

Esses são novos instrumentos de uma moderna governança, em formação, nos quais se inserem os conselhos de gestão de áreas protegidas, enquanto exemplo de participação social, sendo estas denominadas de Unidades de Conservação (UC), seguindo as premissas do Sistema Nacional de Unidades de Conservação (SNUC), instituído pela Lei ${ }^{\circ}$ 9.985/2000 (Brasil, 2000).

O SNUC caracteriza Unidade de Conservação (UC) como: espaço territorial e seus recursos ambientais, incluindo as águas jurisdicionais, com características naturais relevantes, legalmente instituído pelo Poder Público, com objetivos de conservação e limites definidos, sob regime especial de administração, ao qual se aplicam garantias adequadas de proteção (Brasil, 2000).

Prevista na Lei do SNUC (Brasil, 2000) está a necessidade, após a criação, da existência de dois instrumentos fundamentais para 0 processo de implementação e gestão: (i) Conselho Gestor e; (ii) Plano de Manejo. Ambos definidores da legitimação de um fazer participativo dentro de toda e qualquer unidade de conservação (Veríssimo, 2009).

Segundo o IBASE (2006), "Os conselhos devem funcionar como espaços públicos de cooperação entre as várias instâncias de poder governamental e a sociedade civil”. Em seu artigo 29, a Lei do SNUC, a criação do Conselho Gestor Consultivo, deliberativos em alguns casos, das UC de Proteção Integral, deve apresentar as seguintes diretrizes: 
Art. 29. Cada unidade de conservação do grupo de Proteção Integral disporá de um Conselho Consultivo, presidido pelo órgão responsável por sua administração e constituído por representantes de órgãos públicos, de organizações da sociedade civil, por proprietários de terras localizadas em Refúgio de Vida Silvestre ou Monumento Natural, quando for 0 caso, e, na hipótese prevista no segundo parágrafo do artigo 42, das populações tradicionais residentes, conforme se dispuser em regulamento e no ato de criação da unidade (SNUC, 2000).

De acordo com o artigo 20, do Decreto $n^{0}$ 4.340/2002 (Brasil, 2002), compete ao Conselho Gestor de Unidade de Conservação:

Art. 20. Compete ao conselho de unidade de conservação:

I - elaborar o seu regimento interno, no prazo de noventa dias, contados da sua instalação;

II - acompanhar a elaboração, implementação e revisão do Plano de Manejo da unidade de conservação, quando couber, garantindo o seu caráter participativo;

III - buscar a integração da unidade de conservação com as demais unidades e espaços territoriais especialmente protegidos e com o seu entorno;

IV - esforçar-se para compatibilizar os interesses dos diversos segmentos sociais relacionados com a unidade;

$\mathrm{V}$ - avaliar o orçamento da unidade e o relatório financeiro anual elaborado pelo órgão executor em relação aos objetivos da unidade de conservação;

VI - opinar, no caso de conselho consultivo, ou ratificar, no caso de conselho deliberativo, a contratação e os dispositivos do termo de parceria com OSCIP, na hipótese de gestão compartilhada da unidade;

VII - acompanhar a gestão por OSCIP e recomendar a rescisão do termo de parceria, quando constatada irregularidade;

VIII - manifestar-se sobre obra ou atividade potencialmente causadora de impacto na unidade de conservação, em sua zona de amortecimento, mosaicos ou corredores ecológicos; e

IX - propor diretrizes e ações para compatibilizar, integrar e otimizar a relação com a população do entorno ou do interior da unidade, conforme o caso. (Brasil, 2002)

O SNUC exige que o número de membros do conselho, em caso de UC Pública, seja igual ao número de membros da sociedade civil ou paritário. O SNUC, neste caso, inclui a iniciativa privada como sociedade civil. Sendo necessário apresentar justificativa, quando não for possível, para compor um conselho paritário.

Os principais benefícios de um Conselho Gestor, quanto atuante, de acordo com o preconiza as UCs, são:

- Aumentar o diálogo e a confiança entre o órgão gestor, comunidade local, órgãos públicos e instituições da sociedade civil na medida em que os conselheiros têm acesso a informações e compreendem as limitações e os desafios para gestão da UC;

- Aumentar a governança e o apoio político da UC junto às comunidades locais, setor privado, ONGs, instituições de pesquisa, entre outros atores;

- Ampliar o conhecimento sobre a região e sobre o contexto políticoinstitucional em que estão inseridas as UCs por meio da contribuição técnica dos conselheiros;

- Aumentar o orçamento destinado às UCs, pois entidades que integram o conselho podem atrair recursos de doações para projetos de fortalecimento da gestão, elaboração e implantação dos Planos de Manejo das UCs.

- Diante do exposto, este trabalho foi direcionado para realizar uma revisão de conceitos entre diversos atores, avaliando uma realidade por ora aplicada no Parque Estadual Marinho de Areia Vermelha (PEMAV/PB), contextualizando aspectos como 
comunidade, território, capital social, política e empoderamento.

Assim, participar na gestão de uma UC exige escolhas filosóficas e ideológicas. A concepção, os critérios e as normas que instituem as UC, definem como “[...] espaço territorial e seus recursos ambientais [...] com características naturais relevantes" (Brasil, 2000), negam a interação entre grupos sociais no espaço protegido, por isso, comunidades localizadas no entorno das UC, ou mesmo no seu interior, foram historicamente excluídas de sua gestão e ainda são direta ou indiretamente atingidas pelas restrições de uso que são impostas, situação ainda mais evidente naquelas de Proteção Integral (Ferreira, 2006).

Porém, acima destas fundamentações, o processo participativo do Conselho Gestor tem como finalidade atuar enquanto espaço público de diálogo ambiental, onde se nivela conceitos, constrói valores a partir do envolvimento dos conselheiros, agrega interesses dos diferentes segmentos sociais (saber popular, acadêmico, técnico entre outros) que utilizam a UC, fortalecendo e promovendo legitimidade ao processo de gestão (Figura 1).

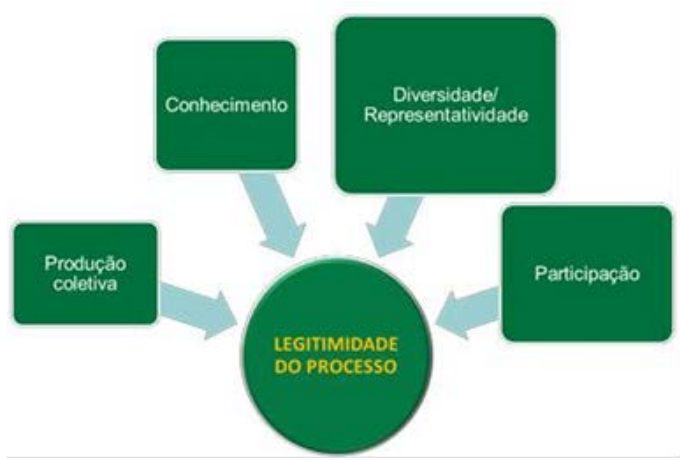

Figura 1. Legitimidade do processo do Conselho Gestor para UCs. Fonte: http://fflorestal.sp.gov.br/unidades-deconservacao/apas/

No caso do Parque Estadual Marinho de Areia Vermelha (PEMAV), esta é uma Unidade de Conservação especificamente marinha, estando aproximadamente a $1 \mathrm{~km}$ da costa do Município de Cabedelo-PB (Figura 2). Possui uma área de 231 ha e perímetro de 8.382,72 m e abrange o Banco de Areia Vermelha e o Banco de Areia Dourada que afloram de acordo com as marés.

A principal motivação para instituir o PEMAV se deu em função da necessidade de gestão do lugar, por parte do governo estadual. Quando da busca pela preservação da biodiversidade encontrada principalmente nos recifes de corais, neste caso, ameaçados pela pesca e pela visitação turística cada vez mais intensa e desordenada. É uma área com especificidade natural que a faz diferenciada de outras áreas, pela existência de uma significativa biodiversidade marinha associada aos recifes de corais, inclusive espécies ameaçadas de extinção (Gondim et al., 2011).

Outros aspectos relacionados a caracterização do PEMAV são relevantes, sendo citados alguns destes: geomorfologia, oceanografia, climatologia, entre outros, cujo estudo científico possibilita a compreensão da gênese, da dinâmica e da evolução da paisagem.

Em sua ação específica, e conforme demonstrada no mapa (Figura 3), por determinação do Ministério Publico Federal, os pontos laranjas caracterizam as boias fixas e os pontos azuis caracterizando a necessidade de existirem placas informativas a serem introduzidas ao longo da Orla Marítima do Município de Cabedelo.

No caso das áreas sublinhadas no interior do perímetro do PEMAV (em cores azul, rosa e verde), estas representam os bancos de areia quando expostos à partir da maré 0,8 m (Areia Vermelha e Areia Dourada). Fase em que ocorre visitação pública transportados, seja em catamarã de passeio ou embarcações de esporte e recreio.

Sendo possível verificar também, a existência de passagens naturais para embarcações de pescadores, intituladas Barretas, sendo a Barreta do Caranguejo (barreta sinalizada no meio da UC, (Figura 3), onde ocorre o maior índice de crimes ambientais relacionados à pesca). 
Este trabalho, em sua composição principal, busca demonstrar o trabalho executado pelo Conselho Gestor do Parque
Estadual Marinho de Areia Vermelha e sua formação discursiva de resultados no período eleito de 2013 a 2015.

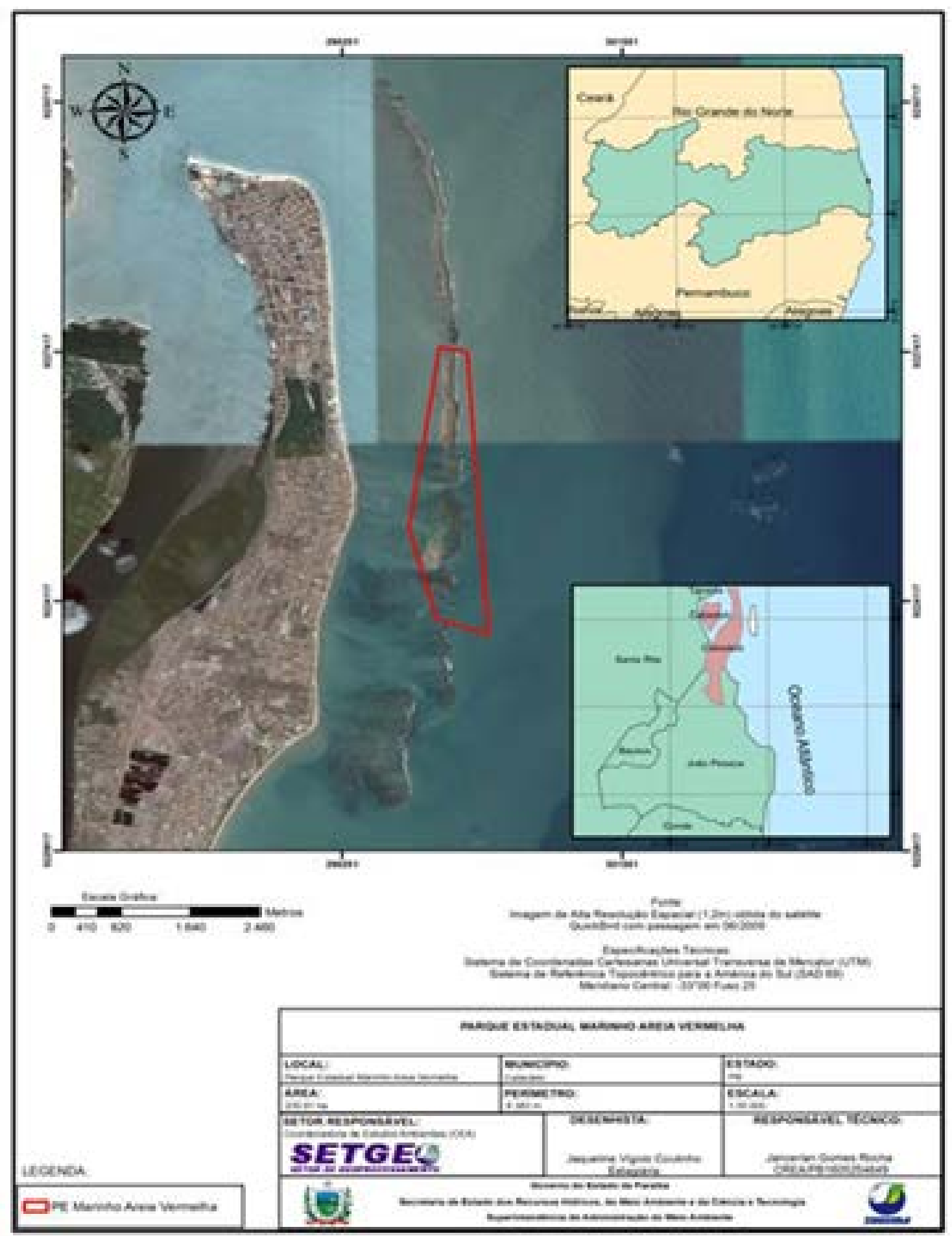

Figura 2. Imagem com destaque do Parque Estadual Marinho Areia Vermelha (PEMAV). Fonte: SETGEO, SUDEMA. Imagem Google Earth (2012). 


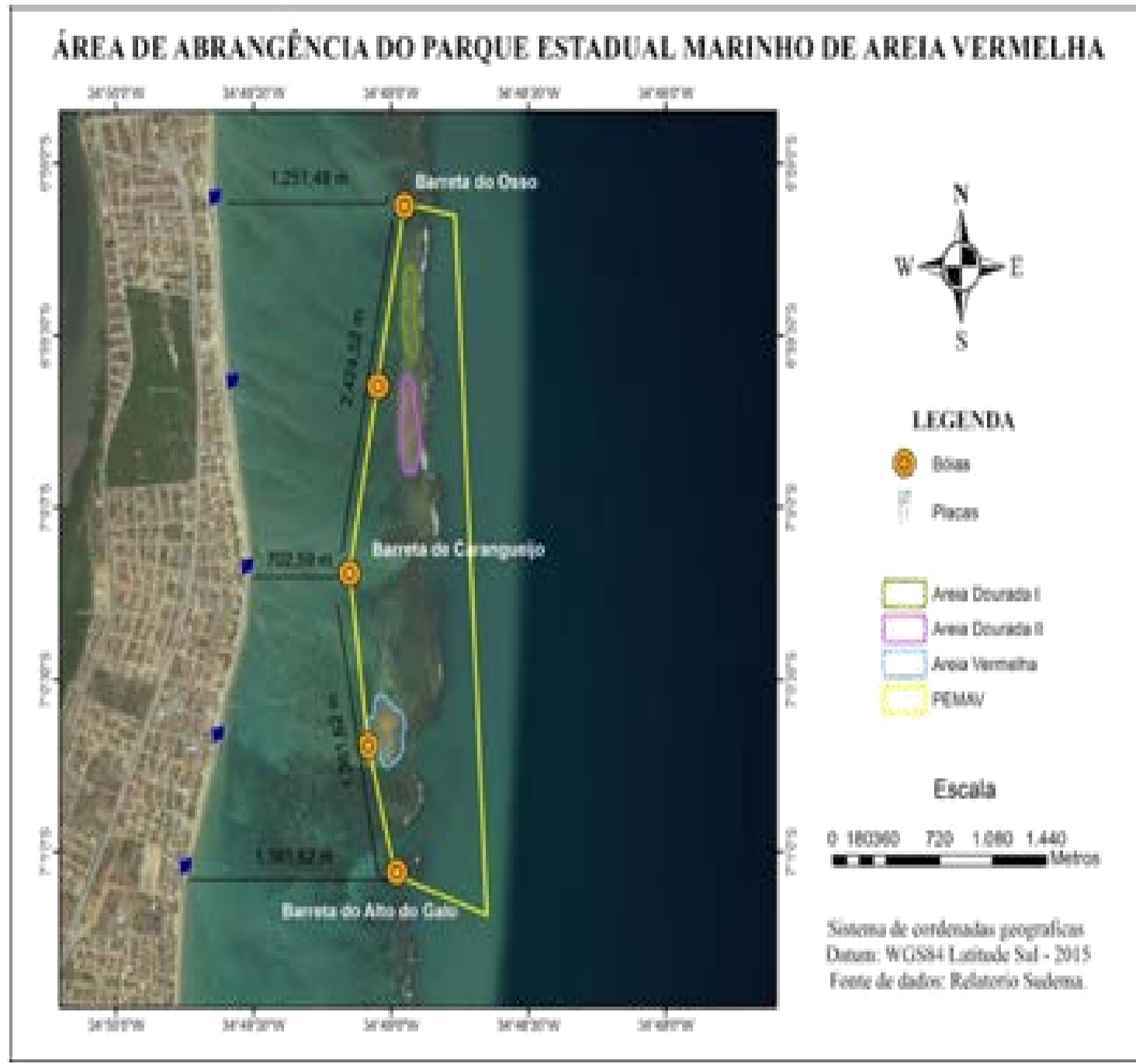

Figura 3. Imagem com destaque das áreas de embarque do Parque Estadual Marinho de Areia Vermelha (PEMAV). Fonte: LEGAT, UFPB. Imagem Google Earth (2015).

\section{Metodologia}

Como forma de reunir informações e descrever todos os fatos e atos existentes, foi utilizado a metodologia da pesquisa participante, bem como, leitura de interpretação de documentos, artigos e livros relativos a questão. Sendo buscado na pratica da vivencia em alguns outros conselhos gestores, como método comparativo e discussão de realidades.

\section{Resultados e discussões}

Da prática discursiva e análise de dados bibliográficos, bem como da participação direta no Conselho Gestor, as observação deverão ser descritas a partir dos relatos historiográficos contidos nas Atas (CEA/SUDEMA e Jornais locais) abaixo:

- Em 2014, através do Termo de Compromisso de Compensação Ambiental firmado entre a SUDEMA e a empresa InterCement, foi instituído a elaboração do Plano de Manejo e a construção da sede mar (Catamarã), ambos para o PEMAV.

- Em novembro 2014, na abertura da II Semana Náutica da Paraíba, o 
município de Cabedelo disponibilizou uma área na orla do município - frente ao PEMAV - de modo ao Estado construir uma sede em terra, que funcionará como base de apoio para a gestão e para o visitante.

- $\quad$ Em março 2015 foi realizada a $1^{\text {a }}$ Oficina "Biodiversidade e Socioeconômica” referente ao Plano de Manejo.

- $\quad$ Em abril de 2015 foi dado entrada na Secretaria do Patrimônio da União - SPU, a solicitação da cessão de uso da área do PEMAV.

- Em maio 2015, a Sudema recebeu a aceitação da fase piloto do Programa Bandeira Azul.

- Em agosto 2015 foi obtido a anuência do projeto da sede PEMAV pelo Conselho Gestor do Projeto Orla do município de Cabedelo.

- Após o I Encontro de Pesquisa sobre Unidades de Conservação Marinha (setembro/2015) no Parque Nacional Fernando de Noronha, foi acordado pela gestora do PEMAV e da Coordenação do Programa Reef Check/BR, em realizar a capacitação e ações de monitoramento dos recifes de corais para monitores ambientais em novembro de 2015.

- Em setembro 2015 foi realizada a $2^{\mathrm{a}}$ Oficina “Zoneamento" referente ao Plano de Manejo.

No que tange o Plano de Manejo, enquanto documento norteador das ações a serem realizadas dentro do PEMAV em consonância com a Lei do SNUC e Florestal e de Crimes Ambientais, torna-se um processo tanto complexo quanto demorado, do ponto de vista da construção de elementos consubstanciais para dirimir duvidas e dirigir ações solidificadas em dados concretos e reais do lugar. Diante de tal fato, e na necessidade de uma urgente intervenção o órgão gestor (SUDEMA) optou por adotar a elaboração do Plano de Ação Emergencial (PAE), de forma a evitar a ampliação da degradação ambiental. Sendo desdobrado para tanto: (i) divisão de grupos de trabalho em eixos temáticos; (ii) reuniões e workshops; (iii) visitas ao local; (iv) leituras e discussões sobre o documento balizador do Plano de Manejo, em construção por empresa contratada, ocorrendo paralelo a construção publica e coletiva do PAE a ser posta em pratica imediatamente ao seu termino. Fato não ocorrido, devido à interferência e intervenções constantes do Ministério Público e Secretaria do Turismo do Estado da Paraíba, deliberando demandas não discutidas ou aprovadas no Conselho Gestor da Unidade de Conservação.

Enquanto discussão sobre a necessidade de existência e atuação do Conselho Gestor de uma Unidade de Conservação, garantida pela Lei do SNUC (Brasil, 2000) e do decreto de criação da própria unidade de conservação (Paraíba, 2000), convém registrar para analise as seguintes questões geradas com esta intervenção direta e não participativa:

- A assinatura do TAC gerou uma desconfiança da necessidade de existência do Conselho Gestor, por parte dos Conselheiros. Chegando muitos a declarar não mais ter interesse em participar de um Conselho Gestor cujo próprio órgão desconsidera a necessidade das suas deliberações;

- A pedido de alguns conselheiros foram solicitados tanto a presença quanto maiores esclarecimentos do grupo participante das audiências, sobre esta "intervenção silenciosa" no Conselho Gestor.

- Outras reuniões foram solicitadas tanto para continuidade das ações postas no Plano de Ação Emergencial, quanto para melhor alinhar as decisões tomadas nas audiências sem participação do Conselho, com aquilo que já vinham sendo apresentadas e discutidas por todos. Não havendo sucesso de atendimento.

- Foi realizado audiência pública na Assembleia Legislativa, por parte do grupo participante da reunião para o TAC, sendo contestado por alguns conselheiros sem muito sucesso de escuta participativa e amistosa, conforme gravação da Audiência Pública pela TV 
Assembleia e matérias veiculadas nas mídias jornalísticas.

- O TAC foi assinado e publicado a revelia do Conselho Gestor e as reuniões encerraram, pela inoperância ou necessidade demonstrada de existência do mesmo.
Seguem destacados na Tabela 1 algumas atividades do Conselho Gestor PEMAV em seu período de funcionamento e imagens de momentos do CGC (Conselho Gestor Consultivo).

Tabela 1. Representações e assentos que formam o Conselho Gestor do PEMAV.

\begin{tabular}{|c|c|c|}
\hline Data & Atividade & Pauta \\
\hline 18 junho 2014 & $1^{\text {a }}$ Reunião Ordinária CGC PEMAV & Posse Conselho Gestor Consultivo \\
\hline 30 julho 2014 & $\begin{array}{c}\cdot 1^{\text {a }} \text { Reunião Grupo de Trabalho Regimento } \\
\text { Interno }\end{array}$ & Ėlaboração do Regimento Interno \\
\hline 03 setembro 2014 & 2ª Reunião Ordinária CGC PEMAV & $\begin{array}{l}\text { Apresentação sobre aspectos } \\
\text { relacionados com o PEMAV e } \\
\text { perspectivas futuras }\end{array}$ \\
\hline 17 outubro 2014 & 1ª Reunião Extraordinária CGC PEMAV & $\begin{array}{l}\text { Aprovação do Regimento Interno } \\
\text { na reunião do CGC PEMAV }\end{array}$ \\
\hline 21 outubro 2014 & $1^{\text {a }}$ Reunião Grupo de Trabalho & Acompanhamento Plano de Manejo \\
\hline 03 novembro 2014 & $3^{\text {a }}$ Reunião Extraordinária CGC PEMAV & $\begin{array}{c}\text { Dinâmicas para capacitação sobre o } \\
\text { PEMAV para os Conselheiros }\end{array}$ \\
\hline 18 novembro 2014 & $3^{a}$ Reunião Ordinária CGC PEMAV & \begin{tabular}{|c|} 
Organização II Semana Náutica/PB \\
e ações para o verão 2014/2015 \\
\end{tabular} \\
\hline 12 fevereiro 2015 & $1^{a}$ Reunião Ordinária CGC PEMAV & $\begin{array}{c}\text { Apresentação dos novos } \\
\text { representantes e explanação sobre } \\
\text { as atividades do CGC }\end{array}$ \\
\hline 24 abril 2015 & 2ª Reunião Ordinária CGC PEMAV & $\begin{array}{c}\text { Explanação sobre o Programa } \\
\text { Bandeira Azul e Programa Reef } \\
\text { Check } \\
\end{array}$ \\
\hline 24 agosto 2015 & $3^{\mathrm{a}}$ Reunião Ordinária CGC PEMAV & \begin{tabular}{|c|} 
Celebração um ano de CGC e \\
definição do workshop para \\
elaboração do Plano de Ação \\
Emergencial (PAE) para o PEMAV
\end{tabular} \\
\hline 07 dezembro 2015 & 4ª Reunião Ordinária & $\begin{array}{c}\text { Apresentação na íntegra do Plano } \\
\text { de Ação Emergencial }\end{array}$ \\
\hline
\end{tabular}

Como resultado visto de todo o processo, podemos colocar em evidencia o "Esquema Analítico de Modalidades de Participação”, apresentado por Serrano (1998):

- Habilitação social e empoderamento. O exercício envolve a participação consultiva um certo nível de empoderamento social. É uma forma de participação na qual a comunidade adquire habilidades e capacidades, fortalecer seus próprios espaços e organizações e agir com um sentido de identidade e própria comunidade. Enquanto o Estado faz levantar questões, influenciar o processo decisório, e aumentar a sua negociação e do diálogo com o setor público.

- Gestionária. Uma vez que o órgão é a esfera superior que tem autonomia pela tomada de decisões. Além disso, por se tratar de um conselho gestor consultivo e não deliberativo. 
- Instrumental. Devido às representações do conselho, que proporciona uma facilidade e dinamismo em diversas articulações, ações, atividades, etc.

- Consultiva. Pelo fato de ser um Conselho representativo para determinadas ações (ex. autorizações de pesquisa na UC, etc.), assim como por promover a comunidade como um todo um momento de diálogo para a elaboração do plano de manejo.

Concordando com o Serrano (1998), quando se refere que nenhuma das quatro formas de participação pode existir em sua forma pura, mas uma poderá e deverá existir em dialogo com as demais ou mesmo, servindo de passagem de uma a outra. Neste caso, podendo variar dependendo do início do ciclo do programa, além do sujeito da participação.

No que concerne ao processo do Conselho Gestor Consultivo do Parque Estadual Marinho de Areia Vermelha (PEMAV), hora formado por instituições públicas e da sociedade civil organizada, qualificada para o debate ambiental e da gestão do lugar. Esta combinação de formas e valores foram postas em prática, não sendo possível precisar os momentos onde uma ou outra forma ocorreram e nem sua transição, por não ser este o objeto de investigação. Porém ficou claro que tanto a forma quanto o formato de participação foi estabelecido e a Lei do SNUC (Brasil, 2000), teve sua pratica deliberada no seu conjunto da obra aqui exposta e confrontada diante das ações externas e impositivas citadas.

\section{Conclusão}

O conselho gestor consultivo, em qualquer instância ou linha de governança, é um instrumento legítimo e necessário tanto de participação e aprendizado para a cidadania, quanto de necessidade de efetivação daquilo que promulga nossa Constituição Federal de 1988. Sendo fato destacar que "o poder emana do povo e cabe ao povo o dever de governar". Neste sentido, conforme Taylor (1998) e Araújo et al. (2015), observa-se que uma sociedade onde as pessoas nem sempre estão dispostas a participar nos assuntos públicos, e quando ocorre, acaba invariavelmente sendo interrompido de forma ditatorial e o governo paternalista acaba por exercer um imenso poder tutelar sobre a necessidade de vida participativa no regime governamental em curso.

A única maneira de defender um conselho democrático, segundo Taylor (1998), é desenvolver "uma cultura política vigorosa que valoriza a participação nos diversos níveis de governo e associações voluntárias”, aproveitando, ao máximo, das aberturas ou instrumentações oferecidas legal e oficialmente pelos atos constitucionais e necessidades dos poderes em ter atores da sociedade civil, dividindo tarefas e responsabilidades, sendo o caso dos conselhos gestores ora citados.

Assim, pode-se descrever que, no caso dos conselhos gestores de unidades de conservação, instituições públicas e civis são chamadas a fazerem-se presentes nas deliberações sobre o fazer em determinada UC, onde se demonstra ter, ou vir a ter interesse nos seus acontecimentos. Estas instituições nomeiam representantes com interesse nas discussões propostas e contribuições no agir, em nome e pela instituição que representa.

Porém, em se buscando entender este processo, assim como, todo e qualquer processo de representatividade no Brasil, o representante não entendendo ou não querendo entender a sua representação, acaba por estar e opinar, a partir do seu interesse, ausentando-se da discussão ou deliberação, quando ela não convém aos seus interesses particulares (Israel et al., 1994; Putnam, 1994; Wallerstein et al., 1998). Deixando de responder por sua instituição, e respondendo por seu próprio conhecimento e interesse. Estas ações fragilizam, por um lado, o próprio propósito de estar representando algo maior, e por outro, corroborando ainda mais, com o estado de mando e desmandos de nossos representantes legais (políticos eleitos), que estão sempre a legislar em causa própria, pelo próprio abandono do seu eleitor. 
No caso do Conselho Gestor do PEMAV, e refletindo de forma sólida sobre sua atuação frente à política paternalista e ditatorial dos eleitos pelo próprio povo para representá-los junto à busca do bem e fazer comum a todos, pode-se dizer que, as ações tidas e contidas neste relato documental, pode ser visto como uma ação de estímulo resposta às necessidades de atuação popular, respondida através da participação coletiva e efetiva nas reuniões e ações deste conselho. Porém, interrompidas e corrompidas, quando do ato "tirano" e "inconteste" dos que, eleitos pelo e para representar o povo, ainda pensam e agem, sendo aceitos, quando veem seus interesses particulares sendo contrariados, mesmo por instrumentos legítimos da democracia participativa.

Assim sendo, este trabalho deixa explicito a necessidade de reflexão sobre o papel da representação social e institucional, e o próprio ato do ser social diante de processos consultivos e deliberativos no âmbito coletivo, contrariado pelo poder político emanado do próprio povo no sentido na condução e não da imposição, ou da força da minoria sobre a maioria, principalmente em se tratando de uma maioria qualificada e representante de instituições e entidades civis.

\section{Referências}

Araújo, E.; Barreto, P.; Martins, H. Áreas protegidas críticas na Amazônia no período de 2012 a 2014. Belém: Imazon, 2015.

Baquero, R. V. A. Empoderamento: questões conceituais e metodológicas. Revista Debates, v. $6, \quad$ n. 1, $\quad$ p. 173-187, 2012. <http://www.seer.ufrgs.br/debates/article/viewFi le/26722/17099>. Acesso em: 26 nov. 2015.

Brasil. Constituição da República Federativa do Brasil de 1988. Disponível em: $<$ http://www.planalto.gov.br/ccivil_03/constitui cao/constituicaocompilado.htm>. Acesso em: 26 nov. 2015.

Brasil. Lei $\mathrm{n}^{\circ}$ 6.938, de 31 de agosto de 1981 . Dispõe sobre a Política Nacional do Meio Ambiente, seus fins e mecanismos de formulação e aplicação, e dá outras providências. Disponível em: <http://www.planalto.gov.br/ccivil_03/leis/1693 8.htm>. Acesso em: 26 nov. 2015.
Brasil. Lei $\mathbf{n}^{0}$ 9.985, de 18 de julho de 2000. Regulamenta o art. 225, § $1^{\circ}$, incisos I, II, III e VII da Constituição Federal, institui o Sistema Nacional de Unidades de Conservação da Natureza e dá outras providências. Disponível em: <http://www.planalto.gov.br/ccivil_03/leis/ L9985.htm>. Acesso em: 26 nov. 2015.

Brasil. Decreto $\mathrm{n}^{0} \mathbf{4 . 3 4 0}$, de 22 de agosto de 2002. Regulamenta artigos da Lei $n^{0} 9.985$, de 18 de julho de 2000, que dispõe sobre o Sistema Nacional de Unidades de Conservação da Natureza - SNUC, e dá outras providências. Disponível em: <http://www.planalto.gov.br/ ccivil_03/decreto/2002/d4340.htm>. Acesso em: 26 nov. 2015.

Brasil. Princípios e diretrizes para a gestão participativa de unidades de conservação. In: Brasil. Programa Áreas Protegidas da Amazônia: gestão participativa do SNUC. Brasília: WWW Brasil, 2004.

Brasil. Instrução Normativa $n^{\mathbf{0}} \mathbf{1 1}$, junho de 2010. Disciplina as diretrizes, normas e procedimentos para a formação e funcionamento de Conselhos Consultivos em unidades de conservação federais. Disponível em: <http://www.icmbio.gov.br/portal/images/ stories/o-que-fazemos/in112010.pdf $>$. Acesso em: 26 nov. 2015.

Câmara, J. B. D. Governança ambiental no Brasil: ecos do passado. Revista de Sociologia e Política, v. 21, n. 46, p. 125-146, 2013. http://dx.doi.org/10.1590/S010444782013000200008

Ferreira, R. S. A Gestão participativa em unidades de conservação: o caso do Parque Estadual Pedra da Boca, em Araruna, PB. João Pessoa: PRODEMA/UFPB, 2006. (Dissertação de Mestrado).

Gondim, A. I.; Dias, T. L. P.; Campos, F. F.; Alonso, C.; Christoffersen, M. L. Macrofauna bêntica do Parque Estadual Marinho de Areia Vermelha, Cabedelo, Paraíba, Brasil. Biota Neotrop., $\quad$ v. 11, $\quad$ n. 2, p. 75-86, 2011. http://dx.doi.org/10.1590/S167606032011000200009

Gohn, M. G. Empoderamento e participação da comunidade em políticas sociais. Revista Saúde e Sociedade, v. 13, n. 2, p. 20-31, 2004. http://dx.doi.org/10.1590/S010412902004000200003

IBASE - Instituto Brasileiro de Análises Sociais e Econômicas. Gestão participativa em unidades de conservação. Rio de Janeiro: IBASE, 2006. Disponível em: $<$ http://www.ibase.br/userimages/ap_ibase_gest ao_01c.pdf>. Acesso em: 26 nov. 2015. 
ICMBio. Práticas Inovadoras na Gestão de Áreas Protegidas. Gestores Empreendedores: Inovação na Gestão de Unidades de Conservação. Brasília: ICMBio, 2014. Edição 1. Disponível em: <http://www.icmbio.gov.br/ praticasinovadoras/images/stories/publicacoes/2 014/publicacao_praticas_2014a.pdf $>$. Acesso em: 26 nov. 2015.

Israel, B.; Checkoway, B.; Schulz, A.; Zimmerman, M. Health education and community empowerment: conceptualizing and measuring perceptions of individual, organizational and community control. Health Education \& Behavior, v. 21, n. 2, p. 149-170, 1994.

http://dx.doi.org/10.1177/109019819402100203

Paraíba. Decreto $n^{0} 21.263$, de 28 de agosto de 2000. Cria o Parque Estadual Marinho de Areia Vermelha e dá outras providências. Diário Oficial do Estado da Paraíba, João Pessoa, 29 ago. 2000.

Putnam, R. Bowling alone: democracy at the end of the Twentieth Century. Princeton: University Princeton Press, 1994.

Santos, R. D.; Lemos, R. C.; Santos, H. G.; Ker, J. C.; Anjos, L. H. C. Manual de descrição e coleta de solo no campo. 5. ed. Viçosa: SBCS/EMBRAPA/CNPS, 2005.

Serrano, J. L. Concepto, formación y autonomia del derecho ambiental. In: Varela, M. D.; Borges, R. C. B. (Orgs.). O novo em Direito Ambiental. Belo Horizonte: Del Rey, 2001.

Taylor, C. A política de reconhecimento. In: Charles, T. Multiculturalismo: examinando a política de reconhecimento. Lisboa: Instituto Piaget, 1998.

Veríssimo, R. A. Conselhos de unidades de conservação: guia sobre sua criação e seu funcionamento. Piracicaba: Imaflora; Belém: Imazon, 2009.

Wallerstein, N.; Bernstein, E. Empowerment education: Freire's ideas adapted to health education. Health Educ Q., v. 15, n. 4, p. 379394. 1988. 